\title{
An Effective Training Program for Registered Sales Clerks Who Sell Over-the-Counter Drugs in Japan: A Preliminary Study
}

\author{
Nami Nakagawa ${ }^{1,2}$, Hitomi Okano ${ }^{1}$, Yuuichi Kyoba ${ }^{1,3}$, Seiichiro Yamada ${ }^{1}$, Hiroaki Suzuki ${ }^{1}$, Masaaki Tsuda ${ }^{1,4}$, \\ Shingo Yano ${ }^{1}$, Mizue Makimura ${ }^{1}$, Kazuo Watanabe ${ }^{1} \&$ Shigeo Yamamura $^{1,5, *}$ \\ ${ }^{1}$ AEON HAPYCOM Comprehensive Training Organization, Japan \\ ${ }^{2}$ Kusuri no Aoki, Japan \\ ${ }^{3}$ Welcia Yakkyoku, Japan \\ ${ }^{4}$ Faculty of Pharmaceutical Sciences, University of Toyama, Japan \\ ${ }^{5}$ Faculty of pharmaceutical Sciences, Josai International University, Japan \\ *Correspondence: Faculty of Pharmaceutical Sciences, Josai International University, Gumyo 1, Togane, Chibe \\ 283-8555, Japan. Tel: 81-485-53-4583. E-mail: s_yama@jiu.ac.jp
}

Received: September 29, 2018 Accepted: October 16, $2018 \quad$ Online Published: October 25, 2018

doi:10.5430/wje.v8n5p203～URL: https://doi.org/10.5430/wje.v8n5p203

\begin{abstract}
Purpose: The Japanese healthcare system has designated registered sales clerks to sell over-the-counter (OTC) drugs. Because of this, the AEON HAPYCOM Comprehensive Training Organization implemented an education program to train registered clerks in 2014. The program is unique; it consists of both lectures and hands-on workshop components. We conducted this study as part of a self-evaluation designed to improve the program.

Methods: Program participants were asked to respond to an evaluation form upon completion. The form was designed to ascertain student perceptions of the program's components (e.g., themes, lecturers, materials, and the hands-on workshop) as well as its applicability to their practice of selling OTC drugs.

Results: We obtained a total of 6,776 responses from 3,388 participants. On average, each of the program's components were rated highly, with the hands-on workshop being rated the highest. There was a weak relationship between the scores for program preparation and its applicability to OTC sales practices.

Conclusion: The program (especially the hands-on workshop component) was highly evaluated by participants. However, we determined that enhancements could be made to the hands-on workshop and other mechanisms to encourage participants to prepare before attending the program.
\end{abstract}

Keywords: registered sales clerk, education, hands-on workshop, over-the-counter drugs

\section{Introduction}

The practice of self-medication is used to treat a variety of common (usually minor) health problems. Patients choose this option to obtain medicines that do not require a prescription. Such medicines are often referred to as “over-the-counter” (OTC) drugs. In some countries, OTC drugs are available in supermarkets and other retail outlets (Zamora et al., 2016). The use of OTC drugs is promoted for treating minor health problems; this reduces the total cost of the national insurance systems in many countries (Dalton \& Byrne, 2017).

Because there is no pharmacy technician system in Japan, pharmacists are responsible for all processes related to the dispensing of self-medications. However, the number of pharmacists working in this field is insufficient to provide adequate services (Nakagawa \& Kume, 2017). Thus, a registered sales clerk system designed to allow other employees to sell OTC drugs on behalf of pharmacists was introduced in 2009 (Nomura et al., 2017).

In Japan, there are two categories in OTC drugs (i.e., drugs that require pharmacist intervention and general OTC drugs) (Nomura et al., 2017). The first kind cannot be sold without assistance from a pharmacist, meaning that potential purchasers must first be qualified to receive them. The second kind, general OTC drugs, are further categorized as first, second, or third class, mainly according to the associated risk factors (Japanese Law Translation. 
The Law on Securing Quality, Efficacy and Safety of Products Including Pharmaceuticals and Medical Devices, 2015). First-class (i.e., Schedule 1) OTC drugs must be sold by a pharmacist, while second (i.e., Schedule 2) and third (i.e., Schedule 3) class OTC drugs can also be sold by a registered sales clerk (Ministry of Health, Labour and Welfare, 2015a). First and second-class OTC drugs must be sold in conjunction with information on drug safety and effective use (Watanabe, 2016).

Registered sales clerks are only permitted to sell second- and third-class OTC drugs. Individuals who wish to become registered sales clerks are required to pass qualification examinations provided by their respective prefectural governors. The examinations are designed to confirm whether an individual has the necessary qualifications pursuant to the provisions of a Ministry of Health, Labour and Welfare (MHLW) ordinance (Ministry of Health, Labour and Welfare, 2015a). The MHLW issues the guidelines for the qualification examinations, which must include the following components: 1) characteristics common to pharmaceuticals and basic knowledge, 2) human body functions and pharmaceuticals, 3) main pharmaceuticals and their effects, 4) laws, ordinances, and systems concerning pharmaceutical affairs, and 5) proper use for pharmaceuticals and safety measures (Ministry of Health, Labour and Welfare, 2015b). The examination contains 120 questions; a correct answer rate of more than $70 \%$ is required for qualification (Ministry of Health, Labor Welfare, 2018).

Before 2015, registered sales clerks were required to have obtained one year of practical experience to sell OTC drugs. This restriction has since been removed. At present, all registered sales clerks must take the 6-hour external training program (those provided by the drugstore or pharmacy where they work are not allowed) twice each year to maintain and improve their qualities as registered sales clerks (Ministry of Labor, Health and Welfare, 2018).

The AEON HAPYCOM Comprehensive Personal Training Organization (AHCPTR) was established to educate pharmacists according to the General Incorporated Association guidelines and certify them as providers through the Pharmacist Credentialing Program as instituted by the Council on Accredited Pharmacists Education Providers (http://www.cpc-j.org/english/index.html).

AHCPTR also provides external training programs for registered sales clerks in accordance with the 2014 MHLW guidelines. The AHCPTR program involves integrated training that includes didactic lectures and a hands-on workshop (most external training programs only consist of lectures). The training program consists of two lectures on diseases and two hands-on workshops (Table 1). In one program, participants are able to learn about two drug categories during one course.

Table 1. AHCPTR Course Program Timetable

\begin{tabular}{lc}
\hline Contents & Time (min) \\
\hline Lecture on the healthcare environment related to registered sales clerks & 20 \\
Session A: & 85 \\
$\quad$ Lecture: Disease and OTC drugs (1) & 15 \\
Question and answer session & 10 \\
Comprehensive test to determine knowledge & 60 \\
Scenario-based hands-on workshop (1) & \\
Break & 85 \\
Session B: & \\
Lecture: Disease and OTC drugs (2) & 15 \\
Question and answer session & 10 \\
Comprehensive test to determine knowledge & 60 \\
Scenario-based hands-on workshop (2) & \\
\hline
\end{tabular}

In the hands-on workshops, participants were divided into small groups and asked to share their experiences selling OTC drugs following a scenario conducted with facilitators.

In this short report, we evaluated our training style based on participant responses and investigated key issue for improving the training program. 


\section{Methods}

\subsection{Sample}

Registered sales clerks who attended the AHCPTR training programs between April 2017 and March 2018 were eligible to participate in this survey. Before it was conducted, a program organizer explained the survey purpose and answering procedures. The organizer also explained that participation was completely voluntarily. Willing participants then signed a consent form and answered the questionnaire.

Data collection and analysis were conducted anonymously and there was no physical intervention with participants. There were no conflicts of interest. All ethics committee criteria from the Faculty of Pharmaceutical Sciences at Josai International University suggested that this survey did not necessarily require review by the ethics committee because it was anonymous, there were no physical interventions, and no conflicts of interest were reported.

\subsection{Study Design}

This was a cross-sectional study with no control.

\subsection{Questionnaire}

Table 2 shows the questionnaire used in this study's survey, in which a Likert scale (i.e., 1 to 4 or 1 to 5) was used.

Table 2. Survey Questionnaire

1) About yourself:

Q1. How long have you been selling pharmaceuticals?

1. Less than 1 year

2. Between 1 and 5 years

3. Between 5 and 10 years

4. Between 10 and 15 years

5. More than 15 years

Q2. Did you prepare before attending the program?

1. Not at all; 2. Very little; 3. Somewhat; 4. Extensively

2) Training program evaluation:

Q3. Theme selection: The program objectives and themes were interesting.

1. Not at all; 2. Not really; 3. Undecided; 4 . Somewhat; 5 . Very much

Q4: Program flow: The program flow was clear and easy to understand.

1. Not at all; 2. Not really; 3. Undecided; 4. Somewhat; 5. Very much

Q5. Materials: The distributed training materials were helpful.

1. Not at all; 2. Not really; 3. Undecided; 4. Somewhat; 5. Very much

Q6. Lecturer: The lecturer adequately explained the learning objectives and other important items.

1. Not at all; 2. Not really; 3. Undecided; 4. Somewhat; 5. Very much

Q7. Hands-on workshop: The hands-on workshop was helpful in achieving the learning objectives.

1. Not at all; 2. Not really; 3. Undecided; 4. Somewhat; 5. Very much

Q8. Applicability: The training program was practical for selling pharmaceuticals.

1. Not at all; 2. Not really; 3. Undecided; 4. Somewhat; 5 . Very much

\subsection{Statistical Analysis}

A statistical analysis was conducted using JMP 13.2.0 (SAS Institute Japan, Japan). 


\section{Results}

A total of 42 training programs were conducted across Japan between April 2017 and March 2018. Of a total of 3,800 registered sales clerks, 3,388 clerks answered the questionnaire, resulting in an effective response rate of approximately $90 \%$. Because each program consisted of two sessions (Table 1), 6,776 responses were obtained and used for the analysis. Table 3 summarizes the training course themes and number of participants in all training programs. The theme usually consisted of a combination of common drug categories (e.g., analgesics, vitamins, and topical drugs).

Table 3. Training Program Themes and the Numbers of Survey Participants

\begin{tabular}{lc}
\hline Theme & Number (\%) \\
\hline Analgesics & $1268(18.7)$ \\
Vitamins & $727(10.7)$ \\
Topical drugs & $710(10.5)$ \\
Pediatric drugs & $590(8.7)$ \\
Sleep improvement/motion sickness & $547(8.1)$ \\
Common cold & $508(7.5)$ \\
Laxatives/hemorrhoids & $508(7.5)$ \\
Eyedrops & $507(6.0)$ \\
Stomach medicines & $398(5.9)$ \\
Analgesics for external use & $370(5.5)$ \\
Smoking-cessation aids & $275(4.1)$ \\
Kanpo for stress and good sleep & $124(1.8)$ \\
Kanpo for obesity reduction & $124(1.8)$ \\
Anemia drugs & $120(1.8)$ \\
Insecticides & $99(1.5)$ \\
\hline
\end{tabular}

Table 4 shows responses to the "About yourself” section. In response to Q1, more than 70\% of all participants had between 1 and 10 years of experience selling OTC drugs, while one-fifth had more than 10 years of experience. Preparation and review before and after the program would be important so participants would be able to apply the studied knowledge and skills to the practical setting of selling OTC drugs. However, responses to Q2 suggests that three-fourths of the participants had almost no preparation before attendance.

Table 4. Responses to "About yourself"

\begin{tabular}{lccccc}
\hline & $\begin{array}{c}\text { Less than } \\
1 \text { year }\end{array}$ & $\begin{array}{c}\text { Between 1 } \\
\text { and 5 years }\end{array}$ & $\begin{array}{c}\text { Between 5 } \\
\text { and 10 years }\end{array}$ & $\begin{array}{c}\text { Between 10 } \\
\text { and 15 years }\end{array}$ & $\begin{array}{c}\text { More than } \\
\text { 15 years }\end{array}$ \\
\hline $\begin{array}{l}\text { Q1. How long have you been } \\
\text { selling pharmaceuticals? }\end{array}$ & 175 & 1206 & 1212 & 431 & 356 \\
& $(5.1 \%)$ & $(35.6 \%)$ & $(35.8 \%)$ & $(12.7 \%)$ & $(10.5 \%)$ \\
Q2 Did you prepare before & 2020 & 2719 & 1772 & 245 & \\
attending the program? & $(29.8 \%)$ & $(40.1 \%)$ & $(26.2 \%)$ & $(3.6 \%)$ & \\
\hline
\end{tabular}

Table 5 shows responses to Q3-Q8 in addition to the average and standard deviations. Answers indicated that our programs were evaluated positively by participants. Most average scores were around 4.0 (the hands-on workshop was rated the highest of all components). 
Table 5. Program Evaluations

\begin{tabular}{|c|c|c|c|c|c|c|c|}
\hline Item & 1 & 2 & 3 & 4 & 5 & Average & SD \\
\hline $\begin{array}{l}\text { Q3. The program objectives and } \\
\text { themes were interesting. }\end{array}$ & $\begin{array}{c}5 \\
(0.0 \%)\end{array}$ & $\begin{array}{c}72 \\
(1.1 \%)\end{array}$ & $\begin{array}{l}587 \\
(7.1 \%)\end{array}$ & $\begin{array}{c}940 \\
(58.1 \%)\end{array}$ & $\begin{array}{c}2251 \\
(33.2 \%)\end{array}$ & 4.22 & 0.64 \\
\hline $\begin{array}{l}\text { Q4. The program flow was clear } \\
\text { and easy to understand. }\end{array}$ & $\begin{array}{c}11 \\
(0.2 \%)\end{array}$ & $\begin{array}{c}95 \\
(1.4 \%)\end{array}$ & $\begin{array}{c}635 \\
(9.4 \%)\end{array}$ & $\begin{array}{c}1884 \\
(27.8 \%)\end{array}$ & $\begin{array}{c}4074 \\
(60.1 \%)\end{array}$ & 4.48 & 0.74 \\
\hline $\begin{array}{l}\text { Q5. The distributed training } \\
\text { materials were helpful. }\end{array}$ & $\begin{array}{c}71 \\
(1.0 \%)\end{array}$ & $\begin{array}{l}473 \\
(7.0 \%)\end{array}$ & $\begin{array}{c}1245 \\
(18.4 \%)\end{array}$ & $\begin{array}{c}2986 \\
(44.1 \%)\end{array}$ & $\begin{array}{c}1952 \\
(28.8 \%)\end{array}$ & 3.93 & 0.92 \\
\hline $\begin{array}{l}\text { Q6. The lecturer adequately } \\
\text { explained the learning objectives } \\
\text { and other important items. }\end{array}$ & $\begin{array}{c}20 \\
(0.3 \%)\end{array}$ & $\begin{array}{c}275 \\
(4.1 \%)\end{array}$ & $\begin{array}{c}1114 \\
(16.4 \%)\end{array}$ & $\begin{array}{c}2967 \\
(43.8 \%)\end{array}$ & $\begin{array}{c}2373 \\
(35.0 \%)\end{array}$ & 4.09 & 0.78 \\
\hline $\begin{array}{l}\text { Q7. The hands-on workshop was } \\
\text { helpful in achieving the learning } \\
\text { objectives. }\end{array}$ & $\begin{array}{c}8 \\
(0.1 \%)\end{array}$ & $\begin{array}{c}69 \\
(1.0 \%)\end{array}$ & $\begin{array}{c}662 \\
(9.8 \%)\end{array}$ & $\begin{array}{c}2091 \\
(30.9 \%)\end{array}$ & $\begin{array}{c}3275 \\
(48.3 \%)\end{array}$ & 4.40 & 0.73 \\
\hline $\begin{array}{l}\text { Q8. The training program was } \\
\text { practical for selling } \\
\text { pharmaceuticals. }\end{array}$ & $\begin{array}{c}4 \\
(0.1 \%)\end{array}$ & $\begin{array}{c}26 \\
(0.4 \%)\end{array}$ & $\begin{array}{c}181 \\
(2.7 \%)\end{array}$ & $\begin{array}{c}1995 \\
(29.4 \%)\end{array}$ & $\begin{array}{c}4509 \\
(66.5 \%)\end{array}$ & 4.63 & 0.56 \\
\hline
\end{tabular}

SD: Standard deviation. Answers were based on the following scale: 1. Not at all; 2. Not really; 3. Undecided; 4. Somewhat; 5. Very much

Obtaining knowledge and skills are not the main program objectives. Rather, it is designed for participants to apply their experiences in providing OTC drugs as proper healthcare professionals. For this reason, responses to Q8 partially reflect program outcomes and were thus considered the most important for program evaluation.

Table 6 shows the rank correlation between Q8 and Q3-Q7, indicating that all pairs correlated well and that correlations were significant at the 5\% level. The highest correlation was found between Q7-Q8, indicating that the hands-on workshop was the most important factor in practically applying program experience.

Table 6. Rank Correlation between Q8 and Q3-Q7

\begin{tabular}{cc}
\hline Pairs & Goodman and Kruskal’s gamma \\
\hline Q3-Q8 & $0.6989(0.6687-0.7292)$ \\
Q4-Q8 & $0.7980(0.7786-0.8174)$ \\
Q5-Q8 & $0.6429(0.6168-0.6690)$ \\
Q6-Q8 & $0.7346(0.7116-0.7577)$ \\
Q7-Q8 & $0.8116(0.7928-0.8304)$ \\
\hline
\end{tabular}

Goodman and Kruskal’s gamma measures rank correlation (Israel, 2009). The 95\% confidence intervals are shown in parentheses.

Figure 1 shows the relationship between program preparations (Q2) and the responses to Q8. Relevance was determined using Goodman and Kruskal's gamma, as follows: 0.2277 (95\% CI: 0.1897-0.2658). Although it was not strong, a significant correlation was found. This suggests that increased preparation would result in better program outcomes. 


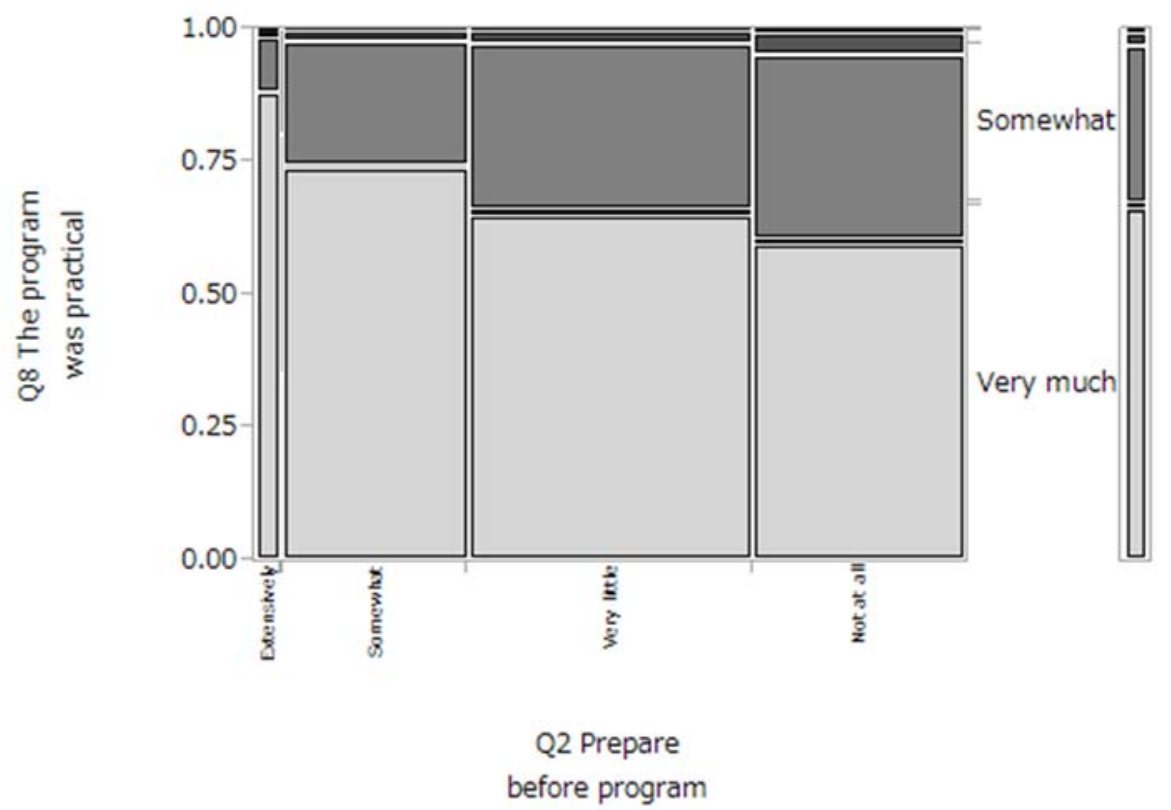

Figure 1. Effects of Preparing for the Program (Q2) on Q8 Scores

Goodman and Kruskal’s gamma: 0.2277 (95\% CI: 0.1897-0.2658) (Israel, 2009).

\section{Discussion}

Some countries use a certificated pharmacy technician system that acts as a pharmacy support workforce. It takes about 3-4 years to be a pharmacy technician through a diploma program. However, education systems and supportive legislation for pharmacy employees, including pharmacy technicians, are quite different among countries (Koehler \& Brown, 2017). The role of pharmacy technicians is to provide technical support, which enables the pharmacist to focus on comprehensive medication review (Fera et al., 2018). Registered sales clerks in Japan provide pharmacy support similar to that provided by pharmacy technicians, but their role in the healthcare system is different from that of pharmacy technicians and more focused on selling OTC drugs. Similar to pharmacy technicians, the registered sales clerks can provide support to pharmacists so the latter can focus on patient care.

Regarding OTC drugs, the US Food and Drug Administration (USFDA) defines an OTC drug as follows: "All these terms refer to medicine that you can buy without a prescription. They are safe and effective when you follow the directions on the label and as directed by your health care professional.” (U.S. Food \& Drug Administration (2018a). The USFDA also provides the document as "Educational Resources: Understanding Over-the-Counter Medicine" (U.S. Food \& Drug Administration (2018b). This indicates that it is necessary to educate individuals who sell OTC drugs (as with registered sales clerks in Japan) to promote rational and safe use. It is thus reasonable to make the certification system for registered sales clerks mandatory in Japan. External education programs should be applicable to practical settings in addition to being highly evaluated by participants.

This study's survey indicated that our programs were highly rated (especially the hands-on workshop) by participants. The program outcome should involve registered sales clerks who are able to select and provide appropriate OTC products for consumers. We did not specifically research this outcome but asked participants about the program's applicability to real practice (see Q8). If participants answered positively to Q8, this indicated that the program provided them with the appropriate skills to sell OTC drugs. Scores for Q8 were most correlated with the hands-on workshop evaluation (see Q7). This indicates that the hands-on workshop (which is unique to our program) is a key component for raising both participant skills in selling OTC drugs and their level of satisfaction with the program. However, few participants extensively prepared for the program (see Q2). This should be addressed because preparation tends to raise Q8 scores, indicating that participants who prepared for the program tended to evaluate the program higher for application in practical settings.

The Q2-Q7 responses were considered related and not statistically independent parameters for Q8. However, Q2 (program preparation) scores were considered independent to Q3-Q8 because Q2 responses involved pre-program 
information, while the others were post-program responses. Even taking this into account, program preparation tended to raise Q8 scores.

This research involved a preliminary survey that asked respondents to self-evaluate their experiences in our training program for registered sales clerks in Japan. Results indicated that the hands-on workshops and program preparation were key issues in reaching better outcomes and higher satisfaction. Further investigation should result in a more feasible and effective education program for registered sales clerks.

\section{Conclusions}

In Japan, the registered sales clerk system has been established to sell OTC drugs. The registered sales clerk role is similar to that of pharmacy technician in other countries, with the biggest differences being that they can only sell OTC drugs in particular categories. The education system for registered sales clerk is quite different from that for pharmacy technicians. They do not earn a diploma and have to take the 6-hour training program twice each year. Therefore, an enhanced training program is necessary. Our education program for registered sales clerks was rated highly among participants, especially the hands-on workshop component. Because most participants considered the program to be applicable to real-life settings, the program flow and contents are considered to have accomplished our objectives. Enhancing the hands-on workshop and adding mechanisms to encourage preparation prior to program attendance are key issues for overall improvement.

\section{Limitations}

Because this research adopted no control in its cross-sectional design, generalizability is not expected. The outcomes may have also been influenced by items such as seminar location or participant workplace (e.g., city centers or rural areas). We intend to further research the relationship between outcomes and participant backgrounds.

\section{References}

Dalton K., \& Byrne S. (2017). Role of the pharmacist in reducing healthcare costs: current insights. Integrated Pharmacy Research and Practice, 6, 37-46. https://doi.org/10.2147/IPRP.S108047

Fera T., Kanel K. T., Bolinger M. L., Fink A. E., \& Iheasirim S. (2018). Clinical support role for a pharmacy technician within a primary care resource center. American Journal of Health-System Pharmacy, 75(3), 139-144. https://doi.org/10.2146/ajhp160646

Israel D. (2009). Data Analysis in Business Research: A Step-By-Step Nonparametric Approach. New Delhi, India: Sage Publications India Pvt. Ltd.

Koehler T., \& Brown A. (2017). A global picture of pharmacy technician and other pharmacy support workforce cadres. Research in Social \& Administrative Pharmacy, 13(2), 271-279. https://doi.org/10.1016/j.sapharm.2016.12.004

Ministry of Health, Labour and Welfare. (2015a). Japanese Law Translation. The Law on Securing Quality, Efficacy and Safety of Products Including Pharmaceuticals and Medical Devices (2015) [Internet]. Retrieved 2018 Sep 20 from http://www.japaneselawtranslation.go.jp/law/detail/?id=2766

Ministry of Health, Labour and Welfare. (2015b). Enforcement Regulations of the Law on Securing Quality, Efficacy and Safety of Products including Pharmaceuticals and Medical Devices (2015) [Internet]. Retrieved 2018 Sep 20 from http://www.japaneselawtranslation.go.jp/law/detail/?id=2768\&vm=04\&re=01

Ministry of Health, Labour and Welfare. 2018 Announcement (2018). Retrieved 2018 Sep 20 from: https://www.mhlw.go.jp/file/06-Seisakujouhou-11120000-Iyakushokuhinkyoku/sikentebiki_4.pdf [in Japanese].

Nakagawa S., \& Kume N. (2017). Pharmacy practice in Japan. Canadian Journal of Hospital Pharmacy, 70(3), 232-242. https://doi.org/10.4212/cjhp.v70i3.1663

Nomura K., Kitagawa Y., Yuda Y., \& Takano-Ohmuro H. (2017). Medicine reclassification processes and regulations for proper use of over-the-counter self-care medicines in Japan. Risk Management and Healthcare Policy, 9, 173-183. https://doi.org/10.2147/RMHP.S98099

U.S. Food and Drug Administration. Educational Resources: Understanding Over-the-Counter Medicine (2018b) [Internet]. $\quad$ Retrieved $2018 \quad$ Sep $\quad 20$ from: https://www.fda.gov/Drugs/ResourcesForYou/Consumers/BuyingUsingMedicineSafely/UnderstandingOver-the 
-CounterMedicines/ucm277845.htm

U.S. Food and Drug Administration. Understanding Over-the-Counter Medicines (2018a) [Internet]. Retrieved 2018 Sep 20 from: https://www.fda.gov/Drugs/ResourcesForYou/Consumers/BuyingUsingMedicineSafely/UnderstandingOver-the -CounterMedicines/default.htm.

Watanabe K. (2016). Non-prescription drugs and self-medication: features and subjects in pharmaceutical education. Yakugaku Zasshi, 136(7), 933-7. https://doi.org/10.1248/yakushi.15-00257-1

Zamora L. F., Gallo M. P., \& Cliquet G. (2016). Selling OTC Drugs in Supermarkets: A Challenge for the European Market, Handbook of Research on Strategic Retailing of Private Label Products in a Recovering Economy. IGI Global. Chapter 19, pp. 469-490. https://doi.org/10.4018/978-1-5225-0220-3.ch019 